\title{
Etanercept-Induced Systemic Lupus Erythematosus in a Patient with Rheumatoid Arthritis
}

\begin{abstract}
Tumor necrosis factor (TNF) is known to play a critical role in the pathogenesis of rheumatoid arthritis (RA). Etanercept is a recombinant soluble fusion protein of TNF $\alpha$ type II receptor and IgG, which acts as a specific TNF- $\alpha$ antagonist. Anti-TNF- $\alpha$ therapy has been an important advance in the treatment of RA. However, induction of autoantibodies in some proportion of patients treated with TNF $\alpha$ inhibitors raised concerns for development of systemic autoimmune diseases such as systemic lupus erythematosus (SLE). Although new autoantibody formation is common with anti-TNF $\alpha$ therapy, there are only rare reports of overt SLE, most of which manifested without major organ involvement and resolved shortly after discontinuation of the therapy. We describe a 55-yr-old Korean woman who developed overt life threatening SLE complicated by pneumonia and tuberculosis following etanercept treatment for RA. This case is to our knowledge, the first report of etanerceptinduced SLE in Korea.
\end{abstract}

Key Words : Lupus Erythematosus, Systemic; Etanercept; TNFR-Fc fusion protein; Arthritis, Rheumatoid

\author{
Min-Jung Kang*, You-Hyun Lee*, \\ Jisoo Lee
}

Department of Internal Medicine, Division of Rheumatology Ewha Womans University College of Medicine, Seoul, Korea

*equal contribution by both authors

Received : 11 April 2005

Accepted : 16 August 2005

Address for correspondence

Jisoo Lee, M.D.

Department of Internal Medicine, Ewha Womans

University College of Medicine, 911-1 Mok-dong

Yangcheon-gu, Seoul 158-710, Korea

Tel : +82.2-2650-6164, Fax : +82.2-2655-2076

E-mail : leejisoo@ewha.ac.kr

\section{INTRODUCTION}

Etanercept is a soluble tumor necrosis factor (TNF $\alpha$ ) receptor fusion protein, which inhibits the biological activity of $\mathrm{TNF} \alpha$. Specific therapy targeting $\mathrm{TNF} \alpha$ has been offered an important advance in the treatment of active rheumatoid arthritis (RA) (1). Although anti-inflammatory and diseasemodifying effect of anti-TNF $\alpha$ therapy are well known, there are concerns for development of serious side effects such as autoimmune disorder, infection and neoplasm as the physiologic actions of TNF $\alpha$ are blocked $(2,3)$.

Drug-induced lupus was firstly reported by Hoffman in 1945 , in a patient who developed hypersensitivity syndrome similar to acute systemic lupus erythematosus (SLE) after taking sulfadiazine (4). Up to 80 kinds of drugs have been known to induce lupus-like syndrome, composing approximately $10 \%$ of the all SLE cases (5). Anti-TNF $\alpha$ agents including etanercept have recently been considered as drugs that can potentially induce lupus, since new autoantibodies such as antinuclear antibodies (ANAs) and anti-double stranded DNA (anti-dsDNA) antibodies were detected in anti-TNF $\alpha$ treated patients (6-8).

Shakoor et al. described the first SLE case among the RA patients treated with etanercept in 2002 (9). Since then, a few similar cases have been reported, that alarmed the clinicians for development of SLE in RA patients treated with anti-TNF $\alpha$ agents (10-13). However, all of the reported cases of anti-TNF $\alpha$-induced SLE was manifested without major organ involvement and resolved shortly after the discontinuation of the therapy. Although a case of tuberculous pleurisy following infliximab therapy was reported in Korea, etanercept associated SLE was not reported previously (14). Herein, we describe a 55-yr-old Korean woman who developed overt life threatening SLE complicated by pneumonia and tuberculosis following etanercept treatment for RA.

\section{CASE REPORT}

A 55-yr-old Korean woman presented with fever and generalized weakness which persisted for 3 months. She had no history of pulmonary tuberculosis or diabetes mellitus. She was diagnosed as seropositive RA $20 \mathrm{yr}$ ago, and had been treated with prednisolone, NSAIDs and methotrexate. Since she had continued active joint inflammation, $25 \mathrm{mg}$ of etanercept twice weekly subcutaneous injection was added to the treatment 8 months ago. Despite improvement of her arthritic symptoms, she began to experience severe fatigue and malaise 3 months ago. Intermittent high fever, myalgia, oral ulcers, gum bleeding, and $10 \mathrm{~kg}$-weight loss were associated. Physical examination revealed cachexic, chronic ill looking woman with severe wasting. Her blood pressure was $130 / 75 \mathrm{mmHg}$, heart rate $88 / \mathrm{min}$, and body temperature $38.1^{\circ} \mathrm{C}$. Her hands demonstrated typical changes of RA with ulnar deviation and deformity of her fingers. Conjunctiva was anemic. Shallow irregular shaped ulcers with hemorrhagic spots were noted 


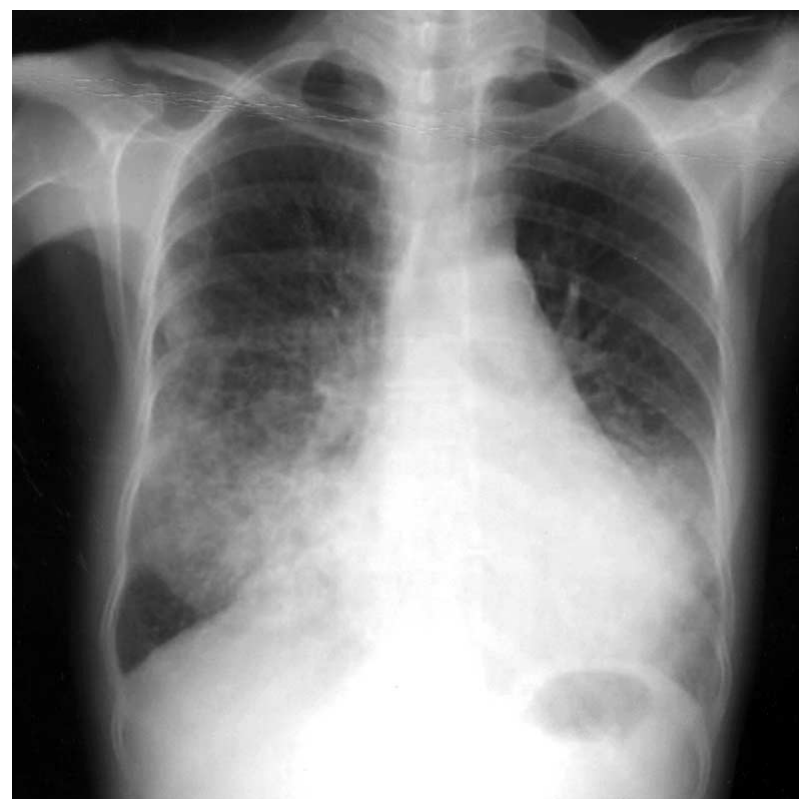

Fig. 1. Chest radiography shows pneumonic consolidation and pulmonary edema in both lung fields

in the oral cavity. On chest examination, crackles were heard over both lung fields. There was no abnormal finding without hepatosplenomegaly in the abdomen. Initial complete blood count revealed hemoglobin of $7.7 \mathrm{~g} / \mathrm{dL}$, white cell count of 3,000/ $\mu \mathrm{L}$ (65\% neutrophil, $26 \%$ lymphocyte), and platelet of $40,000 / \mu \mathrm{L}$. Peripheral blood smear showed no abnormal hematologic cells. Erythrocyte sedimentation rate was $11 \mathrm{~mm} /$ $\mathrm{hr}$ and $\mathrm{C}$-reactive protein was positive at $0.6 \mathrm{mg} / \mathrm{dL}$ (normal $<0.3$ ). Blood chemistry values revealed a total protein of 6.6 $\mathrm{g} / \mathrm{dL}$, albumin of $2.4 \mathrm{~g} / \mathrm{dL}$, BUN $17 \mathrm{mg} / \mathrm{dL}$, creatinine 0.6 $\mathrm{mg} / \mathrm{dL}$, AST $447 \mathrm{IU} / \mathrm{L}$, and ALT $113 \mathrm{IU} / \mathrm{L}$. Creatine kinase was elevated to $253 \mathrm{IU} / \mathrm{L}$. Urinalysis revealed one positive for protein. ANA was positive at a titer of 1:640, staining speckled pattern, and rheumatoid factor was positive at 2,180 IU/ $\mathrm{mL}$ (normal $<15 \mathrm{IU} / \mathrm{mL}$ ). Anti-dsDNA was positive at 14.2 $\mathrm{IU} / \mathrm{mL}$ (normal $<10 \mathrm{IU} / \mathrm{mL}$ ). Antibodies against ribonucleoprotein and Ro/SS-A were positive, but La/SS-B and Smith were negative. C3 was $19.2 \mathrm{mg} / \mathrm{dL}, \mathrm{C} 4$ was $9.9 \mathrm{mg} / \mathrm{dL}$. Symmetrically narrowed joint spaces, bony erosion, and osteopenia were shown in hand radiography suggesting chronic RA with destructive change. Chest radiography revealed pneumonia and pulmonary edema in both lung field (Fig. 1). Chest CT showed pneumonia, pulmonary edema, and pleural effusion with pulmonary hemorrhage suggestive of lupus pneumonitis (Fig. 2). Bone marrow examination was normal except for increased megakaryocyte without evidence of hematologic malignancies.

A diagnosis of SLE with major organ involvement with pneumonitis and thrombocytopenia was made. Etanercept was discontinued and high dose corticosteroid was started. Lupus pneumonitis complicated with pulmonary hemorrhage

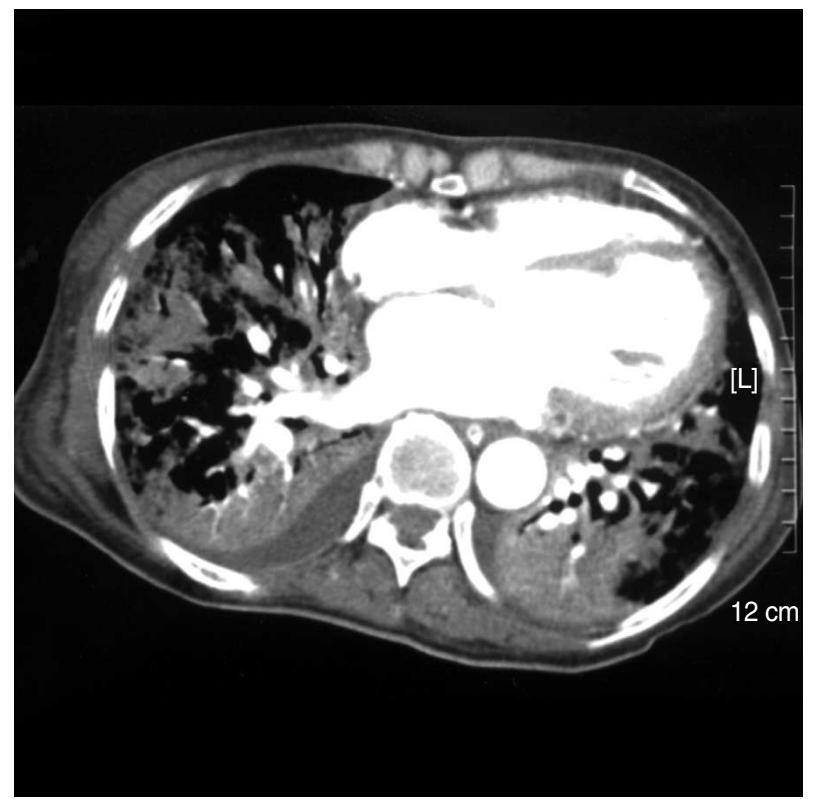

Fig. 2. Chest CT shows pneumonic consolidation, pulmonary edema, and pleural effusion or possible pulmonary hemorrhage.

was improved with corticosteroids treatment. However, residual lung infiltration remained. Bronchoscopic cell culture and PCR of sputum revealed coexistent adenoviral infection, and acyclovir was instituted. Two month later, her general condition markedly improved. However, she was complicated by unilateral pleural effusion, which showed positive for acidfast bacilli PCR. Anti-tuberculous therapy of isoniazid, ethambutol, rifampin, and pyrazinamide was started. She is maintained on prednisolone $20 \mathrm{mg} /$ day, hydroxychloroquine 300 $\mathrm{mg} /$ day, and nabumetone $1 \mathrm{~g} /$ day with minimal symptoms upon 12 months of follow up. However, she still had high titers of ANA and anti-dsDNA antibodies.

\section{DISCUSSION}

$\mathrm{TNF} \alpha$ is an important pro-inflammatory cytokine that can cause inflammation and bony erosion in RA. TNF $\alpha$ inhibitors, such as infliximab, etanercept, and adalimumab were shown to be very effective in reducing synovial inflammation and retarding structural damage in RA patients. Anti-TNF $\alpha$ therapy has opened a new era in treatment of RA, and is being used more and more in current rheumatologic practice. Although TNF $\alpha$ inhibitors are effective therapy for RA, the concerns for serious side effects have been also raised. Adverse events that can potentially occur in anti-TNF $\alpha$ treated patients include tuberculosis, bacterial sepsis, heart failure, hematologic malignancy, and systemic autoimmune disease such as SLE and systemic sclerosis (15).

Autoantibody formation was reported at high frequency in anti-TNF $\alpha$ treated patients. In RA patients treated with 
infliximab, ANA developed in 29-76.7\% and anti-dsDNA in $10-29 \%(7,8,16,17)$. Also in etanercept treated RA patients, $11-36.3 \%$ patients had developed ANA, and 5-15\% developed anti-dsDNA $(16,18,19)$. In Crohn's disease, autoantibody development and infliximab-induced SLE were reported (20-24). Shakoor et al. first reported four cases of etanercept-induced SLE in a series of RA patients in 2002 (9). Swale et al. also reported a case of SLE following 12 months of etanercept therapy in the following year (10). In the previous reports, timing of the onset and offset of the SLE features strongly supported a drug related effect of etanercept. In these patients, SLE developed after mean 7.7 months (range 3-24) of commencing etanercept therapy, and were all women. Most common clinical feature of SLE was skin rash. There was no significant life threatening organ involvement such as kidney, lung, heart and central nervous system. The SLE features were resolved rapidly on stopping the treatment. The British Society for Rheumatology recommends stopping anti$\mathrm{TNF} \alpha$ therapy and appropriate treatment if symptoms of an SLE-like syndrome develop on anti-TNF treatment (25).

The pathogenesis of anti-TNF $\alpha$ in development of SLE has not been yet clarified. Cairns et al. explained that TNF $\alpha$ may up-regulate the cellular expression of the adhesion molecule $\mathrm{CD} 44$, which has a role in the clearance of apoptotic neutrophil by phagocyte. Reduced CD 44 expression by anti-TNF $\alpha$ can potentially induce SLE by abnormal clearance and exposure to apoptotic materials $(12,26)$. Long term exposure over 30 weeks to infliximab has been suggested as a factor that can lead to SLE in one study (17). Although autoantibody formation is quite prevalent in anti-TNF $\alpha$ treated patients, overt clinical syndrome of SLE is rare, suggesting development of SLE in patients treated with anti-TNF $\alpha$ have certain genetic or environmental factors predisposing for systemic autoimmune diseases.

As in our case, severe life-threatening SLE with major organ involvement can occur after etanercept therapy. Risk factors for development of systemic autoimmune diseases should also be evaluated before starting anti-TNF $\alpha$ therapy, as screening for tuberculosis recommended before anti-TNF $\alpha$ treatment.

\section{REFERENCES}

1. Olsen NJ, Stein CM. New drugs for rheumatoid arthritis. $N$ Engl J Med 2004; 350: 2167-79.

2. Roberts L, Mccoll GJ. Tumor necrosis factor inhibitors: risks and benefits in patients with rheumatoid arthritis. Intern Med J 2004; 34: 687-93.

3. Choi BR, Kang TY, Joung CI, Lee HS, Uhm WS, Kim TH, Jun JB, Yoo DH, Bae SC. The efficacy and safety of etanercept in patients with active rheumatoid arthritis receiving methotrexate. Korean $J$ Med 2004; 66: 513-20.

4. Hoffman BJ. Sensitivity to sulfadiazine resembling acute disseminat- ed lupus erythematosus. Arch Dermatol Syphilis 1945; 51: 190-2.

5. Antonov D, Kazandjieva J, Etugov D, Gospodinov D, Tsankov N. Drug-induced lupus erythematosus. Clin Dermatol 2004; 22: 157-66.

6. Pisetsky DS. Tumor necrosis factor a blockers and the induction of anti-DNA autoantibodies. Arthritis Rheum 2000; 43: 2381-2.

7. Charles PJ, Smeenk RJ, De Jong J, Feldmann M, Maini RN. Assessment of antibodies to double-stranded DNA induced in rheumatoid arthritis patients following treatment with infliximab, a monoclonal antibody to tumor necrosis factor $\alpha$. Arthritis Rheum 2000; 43: 238390.

8. Eriksson C, Engstrand S, Sundqvist KG, Rantapää-Dahlqvist S. Autoantibody formation in patients with rheumatoid arthritis treated with anti-TNF a. Ann Rheum Dis 2005; 64: 403-7.

9. Shakoor N, Michalska M, Harris CA, Block JA. Drug-induced systemic lupus eythematosus associated with etanercept therapy. Lancet 2002; 359: 579-80.

10. Swale VJ, Perrett CM, Denton CP, Black CM, Rustin MH. Etanercept-induced systemic lupus erythematosus. Clin Exp Dermatol 2003; 28: 604-7.

11. Carlson E, Rothfield N. Etanercept-induced lupus-like syndrome in a patient with rheumatoid arthritis. Arthritis Rheum 2003; 48: 1165-6.

12. Cairns AP, Duncan MK, Hinder AE, Taggart AJ. New onset systemic lupus erythematosus in a patient receiving etanercept for rheumatoid arthritis. Ann Rheum Dis 2002; 61: 1031-2.

13. Debandt M, Vittecoq O, Descamps V, Le Löet X, Meyer O. AntiTNF- $\alpha$-induced systemic lupus syndrome. Clin Rheumatol 2003; 22: 56-61.

14. Lee YS, Jung JO, Hong JH, Seo YI, Eom KS, Jang SH, Jung KS. Occurrence of tuberculous pleurisy associated with infliximab therapy. Korean J Med 2004; 67: 421-4.

15. Via CS, Shustov A, Rus V, Lang T, Nguyen P, Finkelman FD. In vivo neutralization of TNF- $\alpha$ promotes humoral autoimmunity by preventing the induction of CTL. J Immunol 2001; 167: 6821-6.

16. Caramaschi P, Biasi D, Colombatti M, Pieropan S, Martinelli N, Carletto A, Volpe A, Pacor LM, Bambara LM. Anti-TNF $\alpha$ therapy in rheumatoid arthritis and autoimmunity. Rheumatol Int 2006; 26: 20914.

17. Bobbio-Pallacini F, Claudia A, Caporali R, Avalle S, Bugatti S, Montecucco C. Autoantibody profile in rheumatoid arthritis during longterm infliximab treatment. Arthritis Res Ther 2004; 6: 264-71.

18. Weinblatt ME, Kremer JM, Bankhurst AD, Bulpitt KJ, Fleischmann RM, Fox RI, Jackson CG, Lange M, Burge DJ. A trial of etanercept, a recombinant tumor necrosis factor receptor: $F$ c fusion protein, in patients with rheumatoid arthritis receiving methotrexate. $N$ Engl J Med 1999; 340: 253-9.

19. Moreland LW, Schiff MH, Baumgartner SW, Tindall EA, Fleischmann RM, Bulpitt KJ, Weaver AL, Keystone EC, Furst DE, Mease PJ, Ruderman EM, Horwitz DA, Arkfeld DG, Garrison L, Burge DJ, Blosch CM, Lange ML, McDonnell ND, Weinblatt ME. Etanercept therapy in rheumatoid arthritis. Ann Intern Med 1999; 130: 478-86.

20. Klapman JB, Ene-Stroescu D, Becker MA, Hanauer SB. A lupus-like syndrome associated with infliximab therapy. Inflam Bowel Dis 2003; 9: $176-8$.

21. Sarzi-Puttini P, Ardizzone S, Manzionna G, Atzeni F, Colombo E, 
Antivalle M, Carrabba M, Bianchi-Porro G. Infliximab-induced lupus in Crohn's disease: a case report. Dig Liver Dis 2003; 35: 814-7.

22. Ali Y, Shah S. Infliximab-induced systemic lupus erythematosus. Ann Intern Med 2002; 137: 625-6.

23. Garcia-Planella E, Domènech E, Esteve-Comas M, Bernal I, Cabré E, Boix J, Gassull MA. Development of antinuclear antibodies and its clinical impact in patients with Crohn's disease treated with chimeric monoclonal anti-TNF $\alpha$ antibodies (infliximab). Eur J Gastroenterol Hepatol 2003; 15: 351-4.

24. Vermeire S, Noman M, Van Assche G, Baert F, Van Steen K, Esters $\mathrm{N}$, Joossens S, Bossuyt X, Rutgeerts P. Autoimmunity associated with anti-tumor necrosis factor alpha treatment in Crohn's disease: a prospective cohort study. Gastroenterology 2003; 125: 32-9.

25. Ledingham J, Deighton C, British Society for Rheumatology Standards, Guidelines and Audit Working Group (SGAWG). Update on the British Society for Rheumatology guidelines for prescribing TNF- $\alpha$ blockers in adults with rheumatoid arthritis (update of previous guidelines of April 2001). Rheumatology 2005; 44: 157-63.

26. Hart SP, Dougherty GJ, Haslett C, Dransfield I. CD44 regulates phagocytosis of apoptotic neutrophil granulocytes, but not apoptotic lymphocytes, by human macrophages. J Immunol 1997; 159: 919-25. 